\title{
STUDI EKSPLORASI PARIWISATA SPIRITUAL DI SENTRA PARIWISATA UBUD, GIANYAR (STUDI KASUS DI UBUD BODYWORK CENTRE DAN YOGA BARN)
}

\author{
I Wayan Putra Aditya \\ I Ketut Suwena \\ I Putu Sudana \\ Email : aditditya33@gmail.com \\ PS. S1 Industri Perjalanan Wisata \\ Fakultas Pariwisata UNUD
}

\begin{abstract}
ABSTRAK
Aktivitas pariwisata spiritual di kawasan pariwisata Ubud saat ini sudah menjadi trend yang seiring semakin berkembangnya industri pariwisata di Ubud. Terdapat dua tempat usaha jasa pariwisata spiritual yang memiliki tingkat kunjungan wisatawan yang meningkat dan sekaligus menjadi pioneer usaha jasa pariwisata spiritual di Ubud, yaitu Ubud Bodywork Centre dan Yoga Barn. Penulis mencari data mengenai elemen produk dari produk pariwisata spiritual di Ubud Bodywork Centre dan Yoga Barn. Penulis juga mencari data mengenai karakteristik dan motivasi wisatawan, serta menggolongkan tipologi wisatawan yang melakukan aktivitas pariwisata spiritual di Ubud Bodywork Centre dan Yoga Barn.

Metode pengumpulan data yang digunakan yaitu observasi, wawancara, kuesioner dan studi kepustakaan. Hasil yang diperoleh berdasarkan pengumpulan data tersebut adalah bahwa elemen produk pariwisata spiritual di Ubud Bodywork Centre dan Yoga Barn dapat dilihat berdasarkan physical plant, service, hospitality, freedom of choice dan involvement. Karakteristik wisatawan yang melakukan aktivitas pariwisata spiritual di Ubud Bodywork Centre dan Yoga Barn didominasi oleh kaum perempuan dengan umur rata-rata 31-40 tahun dan mereka yang datang dengan motivasi yang terdiri atas motivasi intrinsik dan motivasi ektrinsik, secara intrinsik motivasi wisatawan adalah combination dan self belive, sedangkan secara ektrinsik adalah reference group/influence dan golongan tipologi wisatawan spiriual di Ubud Bodywork Centre dan Yoga Barn tergolong tipe Drifter dan Eksplorer. Disarankan untuk tokoh-tokoh pendahulu spiritual Ubud maupun pemilik usaha jasa pariwisata spiritual di Ubud untuk memfasilitasi orang lokal yang mempunyai keahlian di bidang aktivitas spiritual namun terkendala di bidang bahasa inggris, agar diberikan pelatihan-pelatihan maupun les yang nantinya agar guru/instruktur yoga maupun kegiatan spiritual lainnya nantinya di ajarkan langsung oleh masyarakat Ubud.
\end{abstract}

\section{Kata kunci :Pariwisata Spiritual, Elemen Produk, Karakteristik, Motivasi, Tipologi}

\section{Latar Belakang}

Salah satu pulau di Indonesia yang unggul dalam bidang pariwisata adalah pulau Bali. Bali sebagai destinasi wisata yang mengedepankan Budaya Bali, yang tiada lain, berdasarkan Agama Hindu dan mengembangkan berbagai aktivitas wisata yang berkaitan dengan hal tersebut. Salah satu aktivitas wisata yang 
masih menjadi icon Bali adalah Pariwisata Spiritual, dimana permintaan untuk melakukan aktivitas pariwisata spiritual di Bali mengambil pasar yang cukup dipertimbangkan, Dengan semakin banyaknya permintaan atas kegiatan pariwisata spiritual saat ini di Bali banyak mempunyai produk-produk yang berbau spiritual dikemas dan dipasarkan ke wisatawan.

Pariwisata spiritual merupakan usaha jasa pelayanan yang melayani keperluan perjalanan seseorang (kelompok) ke destinasi wisata, terutama destinasi yang berkaitan dengan aktivitas spiritual,seperti : yoga, pilgrimage, dan sebagainya (Titib,2006 dalam Nararya, 2012). Pariwisata spiritual juga merupakan salah satu bentuk dari kegiatan pariwisata tertua, dan terlibat dalam sektor yang signifikan berkembang dari pasar pariwisata global. Saat ini orang barat mendominasi melakukan perjalanan spiritual ke Timur untuk mencari ketenangan batin melalui praktik spiritual lintas agama. Seperti yang dikemukan oleh Wayan Wijayasa (dalam nararya 2012), seorang narasumber dari Akademi Pariwisata Denpasar, pada seminar International Bali-India Yoga Festival, menyatakan bahwa pariwisata spiritual berkembang pesat di Bali. Tahun 2007, di desa Ubud saja, ada 14 hotel yang menawarkan kelas Yoga, dan jumlah ini terus berkembang. Seperti di daerah Ubud Kabupaten Gianyar, Bali yang saat ini menjadi tujuan orang Barat untuk melakukan aktivitas spiritual.

Ubud terkenal dengan produk spiritual yoga dikarenakan permintaan aktivitas pariwisata spiritual (yoga) sangat tinggi. Selain yoga harian di hotel, di kawasan wisata Ubud juga ada tempat untuk melakukan aktivitas yoga dengan aliran-aliran yang berbeda, seperti Ubud Bodyworks Centre dan Yoga Barn. Ubud
Bodyworks Centre berlokasi di Jalan Hanoman, Padang Tegal, dikelola oleh bapak Ketut Arsana seorang healer yang mengarah kepada kesehatan jasmani dan rohani dengan melakukan kelas Kundalini Tantra Yoga. Berlatih tantra yaitu latihan rohani yang mengangkat manusia ke dalam suatu proses yang memperluas pikiran. Yanta yaitu simbol yang diwujudkan oleh manusia untuk mengkonsentrasikan batinnya ke hadapan Tuhan Yang Maha Esa dan mantra merupakan sebuah perkataan yang keluar untuk ke tuhan yang Maha Esa (siva) dan melakukan Puja, tari spiritual, meditasi, puasa, nyanyian, dan yoga.

Yoga Barn berlokasi di Jalan Raya Pengosekan Ubud mempunyai aktivitas pariw.isata spiritual seperti kelas yoga harian dengan gerakan yoga tradisional seperti Classic hatha, Power yoga, Pranayama, Restorative, Iyengar, Yin and Anusara. Selain gerakan yoga para yogi juga diarahkan untuk meditas, mendengarkan nyanyian suci dan tarian suci. Melihat dua tempat usaha jasa pariwisata spiritual yang berlokasi masih dalam satu kelurahan, jumlah kunjungan yang tinggi dengan produk yang hampir sama, pangsa pasar yang sama bisa berkembang sangat pesat dibandingkan dengan tempat yoga lainnya di Ubud, sehingga ada ketertarikan untuk mengeksplorasi dari dua sisi yaitu dari sisi produk yang ditawarkan dan dari wisatawan yang melakukan aktivitas pariwisata spiritual.

\section{Metode}

Ubud Bodywork Centre dan Yoga Barn berlokasi di Ubud, Jl. Padang Tegal dan Jalan Raya Pengosekan Ubud. Tinjauan pustaka yang digunakan adalah tinjauan tentang studi 
eksplorasi dari Ikhsan (2010), tinjauan tentang pariwisata spiritual dengan teori Pendit (1994), tinjauan tentang The Element of Tourism Product dari Smith (1994), tinjauan tentang karakteristik dari Suwena dan Widyatmaja (2010), teori motivasi dengan teori Haq\&Jack (2006), tinjauan tentang tipologi wisatawan dengan teori Cohen (1972).

Teknik pengumpulan data yang digunakan yaitu observasi, wawancara, kuesioner, studi kepustakaan dengan teknik penentuan informan menggunakan purposive sampling dengan jumah sampel yang dijadikan respoden sebanyak 35 orang di Ubud Bodywork Centre dan 35 orang di Yoga Barn.

\section{Hasil}

Ubud Bodywork Centre dengan aliran Kundalini Tantra Yoga meiliki arsitektur bangunan dengan konsep Bali (sikut satak) yang mendesain studio yoga yang sesuai dengan alirannya yaitu Kundalini Tantra Yoga, menggunakan aksesoris yang berhubungan dengan Dewa Siwa dan didukung dengan lingkungan yang berada di tengah-tengah kehidupan masyarakat Ubud dengan service staff yang sudah sesuai dengan tugas dan jawab yang ditentukan, ditambah pelayanan ekstra (Hospitality) staff kepada wisatawan dalam bentuk senyum, sopan, dan disiplin. Ubud Bodywork Centre memberikan kebebasan memilih untuk wisatawan seperti kebebasan memilih kegiatan spiritual yang wisatawan inginkan dan kebebasan memilih instruktur yoga yang wisatawan inginkan. Ubud Bodywork Centre mempunyai spesial yoga yang memperbolehkan wisatawan ikut terlibat yaitu pada saat hari raya siwaratri dan nyepi.
Yoga Barn dengan arsitektur bangunan klasik dengan desain campuran joglo, jawa, rumah sumatra dan bali dengan desain studio yoga terkait dengan aliran-aliran yang diaplikasikan dan didukung dengan lingkungan persawah yang berguna untuk relaxsasi. Service karyawan di yoga Barn dilakukan sesuai dengan devisi masing-masing serta karyawan memberikan tambahan ekstra pelayanan dengan senyum, menunjukan rasa hormat dan sikap respon cepat terhadap wisatawan. Wisatawan di Yoga Barn diberikan kebebasan memilih aktivitas dan instruktur yoga sesuai dengan mereka inginkan. Yoga Barn juga memiliki event tahunan (Bali Spirit Fest) yang mengajak wisatawan ikut terlibat di dalamnya.

Dilihat dari sisi wisatawan yang ditinjau dari karakteristik wisatawan, motivasi wisatawan dan tipologi wisatawan sebagai berikut :

(1) Karakteristik wisatawan yang melakukan aktivitas pariwisata spiritual di Ubud Bodywork Centre berdasarkan asal negara didominasi oleh Australia, jenis kelamin perempuan dengan rata-rata umur 31-40th, pekerjaan pegawai swasta, tingkat pendidikan S1, dengan tujuan datang ke Ubud "spiritual, jumlah pembelian produk 1 kali, melakukan perjalanan individu dan teman perjalanan dengan teman.

(2) Motivasi wisatawan di Ubud Bodywork Centre secara intrinsik sense of interconektednest dan culture \& sub culture/learning. Secara Ektrinsik yaitu Reference group/influence.

(1) Karakteristik wisatawan di Yoga Barn menurut asal negara didominasi oleh Amerika dengan jenis kelamin perempuan, umur rata-rata 31-40th, pekerjaan sebagai pengusaha, dengan tingkat pendidikan S1, datang ke ubud dengan tujuan mencari kesehatan, dengan jumlah 
pembelian produk sebanyak 1 kali, pengorganisasian perjalanan secara individu dan teman perjalanan sendiri.

(2) Motivasi wisatawan yang melakukan aktivitas pariwisata spiritual di Yoga Barn secara intrinsik Self belive dan secara ektrinsik Reference group/influence.

Golongan tipologi wisatawan yang melakukan aktivitas pariwisata spiritual di Ubud Bodywork Centre dan Yoga Barn pada tabel berikut,

Tipologi Wisatawan Spiritual di Ubud Bodywork Centre

\begin{tabular}{llcc}
\hline & & \multicolumn{2}{c}{ Jumlah } \\
\cline { 3 - 4 } No & Spiritual Type & Orang & $\begin{array}{c}\text { Kontribusi } \\
(\%)\end{array}$ \\
\hline 1 & Drifter & 18 & $51,4 \%$ \\
2 & Eksplorer & 18 & $51,4 \%$ \\
3 & Individual Mass & 3 & $8,6 \%$ \\
& $\begin{array}{l}\text { Tourist } \\
4\end{array}$ & & \\
& $\begin{array}{l}\text { Organized-Mass } \\
\text { Tourist }\end{array}$ & 3 & $8,6 \%$
\end{tabular}

Tipologi Wisatawan Spiritual di Yoga Barn

\begin{tabular}{llcc}
\hline \multirow{2}{*}{ No } & Spiritual Type & Orang & $\begin{array}{c}\text { Kontribusi } \\
\text { (\%) }\end{array}$ \\
\cline { 3 - 4 } & & 13 & $37,1 \%$ \\
\hline 1 & Drifter & 13 & $37,1 \%$ \\
2 & Eksplorer & 6 & $17,1 \%$ \\
3 & Individual Mass & & \\
& Tourist & & $17,1 \%$ \\
4 & $\begin{array}{l}\text { Organized-Mass } \\
\text { Tourist }\end{array}$ & 6 &
\end{tabular}

Jadi golongan tipologi wisatawan yang melakukan aktivitas pariwisata spiritual di Ubud Bodywork Centre dan Yoga Barn tergolong Drifter \& Eksplorer.

\section{Pembahasan}

Berdasarkan Purana Markandheya, nama Ubud berasal dari nama sungai Wos yang tepat berada di bawah Pura Gunung Lembah. Sungai Wos sebelah barat diyakini oleh masyarakat setempat untuk tempat pembersih (penyucian) bila ada odalan pada pura-pura di Ubud, sedangkan sungai sebelah timur dipercaya sebagai air pembersih diri dari segala mala (kotoran) jasmani maupun rohani. Kedua Sungai Wos Barat dan Wos Timur bertemu menjadi satu disebuah lokasi yang disebut dengan campuhan. Arti kata "Wos" ini pada isi lontar Markandya Purana, "Wos"menjadikan "Usadi", "Usadi" menyebabkan "Usada", dan "Usada"menjadikan "Ubad" atau obat, dan dari kata "Ubad" ini kemudian ditranskripsikan menjadi Ubud dalam Prayogi, 2012.

Ubud Bodywork Centre yang berlokasi di Jalan Hanoman , No.25, Padang Ubud, merupakan usaha jasa pariwisata yang bergerak di bidang aktivitas pariwisata spiritual yang didirikan tahun 1987 oleh Bapak Ketut Arsana dengan produk unggulan Kundalini Tantra Yoga dengan aktivitas yoga, meditasi, nyanyian suci dan tarian dengan guru spiritual berasal dari Ubud dan dari negara-negara luar.

Yoga Barn yang berlokasi di kawasan pariwisata Ubud, tepatnya di Jalan raya Pengosekan Ubud, Gianyar. Berdasarkan sejarahnya Yoga Barn mulai berdiri pada tahun 2007 yang diinisiasi oleh seorang tokoh pemuda lokal Desa Ubud yang bernama I Kadek Gun. Yoga Barn memberikan program secara komperhensif melalui makan sehat, tubuh, pikiran dan jiwa. Aktivitas yang disediakan yoga, tarian,meditasi dan nyanyian.

Elemen produk di Ubud Bodywork 
Centre \& Yoga Barn.

Elemen Produk Pariwisata Spiritual Ubud Bodywork Centre

Physical Plant : Arsitektur bangunan style Bali, desain studio sesuai aliran \& berada di tengah-tengah kehidupan masyarakat Ubud.

Service: Tugas dan tanggung jawab staff, kinerja instruktur yoga

Hospitality : Ekstra tambahan pelayanan sudah diterapkan, seperti; senyum, sapa, ramah dan sikap respon cepat staff terhadap wisatawan.

Freedom of Choice : Wisatawan diberikan kebebasan memilih seperti memilih aktivitas dan memilih instruktur yoga.

Involvement : Pihak Ubud Bodywork melibatkan wisatawan dalam event yang diselenggarakan.

Elemen Produk Pariwisata Spiritual Yoga Barn

Physical Plant : Arsitektur bangunan di yoga barn menggunakan desain klasik dari beberapa style bangunan nusantara, kelas mengusung konsep sesuai aliran dan berada di tengah persawahan.

Service : Yoga barn dengan staff yang mempunyai tugas dan tanggung jawab masing-masing, dan menjalankan tugasnya sesuai pada devisi masing-masing.

Hospitality : Tambahan ekstra dari pelayanan di Yoga seperti senyum saat melihat wisatawan datang, sopan, ramah dan sikap cepat ketika ada wisatawan membutuhkan pertolongan.

Freedom of Choice : Kebebasan memilih yang diberikan seperti; kelas yoga, meditasi, tarian, makanan sehat dan event.

Involvement : Yoga Barn mengajak wisatawan terlibat dalam event tahunannya yaitu Bali Spirit Festival.

Karakteristik Wisatawan di Ubud Bodywork

\section{Centre dan Yoga Barn}

Karakteristik wisatawan di Ubud Bodywork Centre di dominasi oleh wisatawan Australia, jenis kelamin perempuan, umur 31-40, pengorganisasian perjalanannya individu dan teman perjalanannya dengan teman

Karakteristik wisatawan di Yoga Barn didominasi oleh wisatawan Amerika, jumlah wisatawan perempuan paling banyak, umur 31-40th, pengorganisasian perjalanannya individu dan teman perjalannya dengan teman.

\section{Motivasi dan Tipologi Wisatawan di Ubud Bodywork Centre dan Yoga Barn}

Ubud Bodywork Centre dengan motivasi intrinsik sense of interconektednest dan culture \& sub culture/learning. Secara Ektrinsik yaitu Reference group/influence. Sedangkan di Yoga Barn secara intrinsik Self belive dan secara ektrinsik Reference group/influence.

Tipologi wisatawan spiritual di Ubud Bodywork Centre dan Yoga Barn yaitu tergolong wisatawan dengan tipologi Drifter dan Eksplorer.

\section{Simpulan}

(1)Arsitektur bangunan di Ubud Bodywork Centre dan Yoga Barn menggunakan arsitektur bangunan Bali, (2) service sesuai dengan tugas dan tanggung jawab, (3) service tambahan ekstra berupa senyum, sapa, ramah diterapkan oleh karyawan, (4) Ubud Bodywork \& Yoga Barn memberikan kebebasan memilih variasi aktivitas dan instruktur, dan (5) Ubud Bodywork dan Yoga Barn melibatkan wisatawan dalam event. Karakteristik wisatawan di Ubud Bodywork Centre dan Yoga Barn didominasi oleh kaum perempuan dengan umur 31-40 tahun, dengan motivasi ektrinsik sense of interconectednest dan culture \& sub culture/learning dan di Yoga Barn 
Self belive. Secara ektrinsik motivasinya sama yaitu Reference group/influence, dengan golongan tipologi Drifter \& Eksplorer.

\section{Saran}

Perlu adanya pelatihan kursus bahasa inggris untuk orang lokal yang punya skill spiritual, yang dibiayai oleh pihak perusahaan.

\section{Daftar Pustaka}

Haq, F dan Jackson, J. 2006. External Factor in Spiritual Tourism Segmentation : A Three Country Study. Australia : Faculty of Business \& Informatics, Central Queensland University.

Pendit, I Nyoman, S. 1994. Ilmu Pariwisata Sebuah Pengantar Perdana. Jakarta : Pradnya Paramita

Pitana, I Gde dan Gayatri,G Putu. 2005. Sosiologi Pariwisata. Yogyakarta:C.V ANDI OFFSET

Smith, Stephen. 1994. Jurnal The Tourism Product. Canada:University of Waterloo

Suwena, IKetut dan Widyatmaja, Ngr I Gst. 2010. Ilmu Pariwisata. Denpasar : Udayana University Press. 